\title{
CONCENTRAÇÃO E DISTRIBUIÇÃO DO RENDIMENTO POR RAÇA NO BRASIL*
}

\author{
Samuel Kilsztajn \\ Manuela Santos Nunes do Carmo ${ }^{* *}$ \\ Gustavo Toshiaki Lopes Sugahara
}

Erika de Souza Lopes ${ }^{* *}$

Sonia Santos Petrohilos

\begin{abstract}
RESUMO O objetivo do trabalho é estudar a concentração racial do rendimento e analisar a distribuição do rendimento no interior das categorias de raça/cor no Brasil em 2001, a partir dos microdados da Pesquisa Nacional por Amostra de Domicílios do IBGE. Apesar do mito da democracia racial, o rendimento no Brasil está concentrado na categoria não negra da população, que inclusive aufere rendimento maior que os negros, mesmo quando controlado o nível de escolaridade dos trabalhadores. Embora o rendimento entre negros seja relativamente melhor distribuído que o rendimento para não-negros e para o Brasil como um todo, essa melhor distribuição é pouco significativa quando comparada a indicadores internacionais. Neste sentido, a má distribuição do rendimento no Brasil extrapola a questão racial e se manifesta também no interior das categorias de raça/cor.
\end{abstract}

Palavras-chave: distribuição do rendimento; justiça racial; negro

Código JEL: D31; D63; J71

* Artigo recebido em 20 de agosto de 2004 e aprovado em 11 de fevereiro de 2005. Os autores agradecem a colaboração de Edna Roland (Unesco), José Luís Petruccelli (IBGE), Moema de Poli Teixeira (IBGE) e Luciana Zilles Lima (PUC-SP); e as sugestões dos pareceristas da Revista de Economia Contemporânea. Trabalho realizado com o apoio do CNPq e da PUC-SP. Apresentado no XIV Encontro Nacional de Estudos Populacionais, 2004.

** Laboratório de Economia Social do Programa de Estudos Pós-Graduados em Economia Política LES/PUC-SP. Samuel Kilssztajn, e-mail: skil@pucsp.br; Manuela do Carmo, e-mail: manucarmo @uol.com.br; Gustavo Sugahara, e-mail: gustavo.toshiaki@gmail.com; Erika Lopes, e-mail: erikaslopes@gmail.com; Sonia Petrohilos, e-mail: ecopol@pucsp.br 


\section{RACE, EQUALITY AND INCOME DISTRIBUTION IN BRAZIL}

ABSTRACT This article analyzes race/ethnic income inequality and income distribution within blacks and within non-blacks in Brazil, 2001. Despite the Brazilian racial democracy myth, income is concentrated by non-black people that moreover earn higher wages than blacks with the same level of education. Although income within blacks is somewhat better distributed than for non-blacks and for Brazilians altogether, this better distribution is not quite significant when compared to international indicators. Therefore, income inequality in Brazil surpasses ethnic origin and emerges for blacks and non-blacks.

Key words: income distribution; racial justice; blacks 


\section{INTRODUÇÃO}

O Brasil é freqüentemente confundido com uma democracia racial porque o preconceito no país aparece muitas vezes como um objeto invisível, sem tensões abertas e conflitos permanentes (Fernandes, 1972, p. 21-26). Na aparente inconsistência das estatísticas, a quase totalidade dos brancos, quando entrevistada, afirma que não se julga racista; mas diz conhecer pessoas próximas que têm preconceito. Da mesma forma, a maioria dos negros entrevistados nega ter sido vítima de discriminação; mas confirma casos de racismo envolvendo familiares e conhecidos próximos. Neste sentido, racista e vítima de racismo, no Brasil, é sempre o outro (Schwarcz, 1998, p. 180-182).

Estima-se que, por imigração compulsória e na qualidade de escravos, desembarcaram no Brasil mais de 4 milhões de africanos entre 1531 e 1850 (IBGE, 1986, p. 58). Em 1890, dois anos após a abolição da escravatura, foram recenseados 2,1 milhões de pretos e 4,6 milhões de mestiços, que somavam $47 \%$ do total da população brasileira (Petruccelli, 2002, p. 24).

Durante a escravidão, mesmo após a interrupção do tráfico negreiro em 1850, a reprodução de escravos no Brasil não era considerada economicamente lucrativa. Neste sentido, a organização familiar dos negros em suas sociedades de origem foi destruída sem que fosse substituída por relações familiares alternativas. A manifestação mais evidente desse desarranjo era o enorme desequilíbrio na proporção entre homens e mulheres escravos. Os homens negros eram, de longe, muito mais numerosos que as mulheres negras (Segato, 1995, p. 449-454).

Por ocasião da abolição, prevalecia a idéia de que o escravo era uma riqueza e que a abolição acarretaria o empobrecimento dos senhores de escravos (Furtado, 2000, p. 141). Durante o período de vigência da Lei do Ventre Livre de 1871, o governo indenizava os senhores de escravos quando a criança atingia 8 anos de idade (Skidmore, 1976, p. 31-32). Em 1888, contudo, a escravidão foi abolida sem que os senhores de escravos fossem indenizados (Skidmore, 1976, p. 54).

Se a indenização dos senhores não foi concretizada, a dos escravos sequer foi pensada. Também não foram tomadas medidas efetivas que possibilitassem aos negros enfrentar a miséria sistemática e a desorganização so- 
cial a que tinham sido submetidos durante os séculos em que serviram como escravos (Fernandes, 1972, p. 29). Na primeira metade do século XX, durante o processo de generalização do trabalho livre e da competição, a grande massa dos descendentes da antiga população escrava ficou condenada a viver na marginalidade econômica (Furtado, 2000, p. 145).

As atuais políticas de ação afirmativa, de caráter temporário e que estão sendo tardiamente implementadas no país, visam compensar a população afro-descendente pelos obstáculos que enfrentaram e continuam enfrentando na afirmação de sua plena cidadania. Neste sentido, vale lembrar que o importante não é a igualdade formal de direitos, mas sim a igualdade de oportunidades de acesso à educação e ao emprego. Lyndon Johnson, que entre 1963 e 1968 implantou nos Estados Unidos as políticas de ação afirmativa introduzidas por Kennedy em 1961, dizia que não bastava garantir aos afro-descendentes o direito de competir com os demais segmentos da sociedade - era necessário também permitir que eles se habilitassem para a competição (Teixeira et al., 2002, p. 21-30).

O objetivo deste trabalho é estudar a concentração racial do rendimento e analisar a distribuição do rendimento no interior das categorias de raça/ cor no Brasil em 2001, a partir dos microdados da Pesquisa Nacional por Amostra de Domicílios do IBGE. A seção 1 apresenta as categorias de raça/ cor utilizadas na pesquisa, a seção 2 a concentração racial do rendimento, o a seção 3 a distribuição do rendimento por raça e a seção 4, por fim, as considerações finais do trabalho.

\section{CATEGORIAS DE RAÇA/COR}

O conceito de raça é uma construção político-social. Como afirma Guimarães (1995, p. 34), o racismo precede a identificação de uma pessoa pela cor. Uma criança ainda não iniciada no preconceito tende a referir-se a uma pessoa desconhecida não pela cor de sua pele, mas pela cor de sua roupa mesmo que essa pessoa seja a única de cor preta em meio a várias outras por nós identificadas como brancas.

Na composição por raça/cor, de acordo com a Pesquisa Nacional por Amostra de Domicílios (PNAD) de 2001 (que exclui a zona rural da antiga região Norte), a categoria autodenominada preta (em questão pré-codifica- 
da: branca, preta, amarela, parda, indígena) representava 5,6\% da população brasileira e a categoria branca, 53,4\%. A categoria parda (mulata, cabocla, cafuza, mameluca ou mestiça de preto com pessoa de outra cor ou raça) representava $40,4 \%$ e as categorias amarela e indígena representavam respectivamente $0,5 \%$ e $0,1 \%$ (IBGE, 2002).

Na PNAD de 1976 e na Pesquisa Mensal de Emprego de julho de 1998, os brasileiros, em questão aberta, se atribuíram respectivamente 136 (Schwarcz, 1998, p. 226-227) e 143 raças/cores diferentes (Petruccelli, 2000, p. 35-38), reveladoras de uma verdadeira “aquarela do Brasil”, na poética referência de Schwarcz. Mas, embora o intenso processo de mestiçagem brasileiro possa ser responsável pelas múltiplas percepções individuais da cor, há que se considerar que a grande maioria dos brasileiros - 95,7\% na pesquisa de 1998 (Petruccelli, 2000, p. 35-38) — mesmo em questão aberta, concentrou-se em apenas seis categorias: branca $(54,2 \%)$, parda $(10,4 \%)$, preta $(4,3 \%)$, negra $(3,1 \%)$ e as ambíguas cores morena $(20,8 \%)$ e morenaclara $(2,9 \%)$, que incluem tanto negros como brancos de cabelo escuro (Telles, 2003, p. 108); outras cinco categorias (amarela, clara, mulata, morena-escura e escura) foram responsáveis por outros 3,5\%. Ou seja, as demais 132 denominações $(143-6-5)$, somadas, representavam apenas $0,8 \%$ da população.

Teixeira (2003, p. 63-64), que confrontou o critério de autodenominação com o critério de atribuição da identidade racial, concluiu que entrevistados e entrevistadores, com base na aparência, compartilham de um mesmo código de identificação étnica. Como disse uma das pessoas entrevistadas, "eu me identifico como negra porque é assim que eu sou percebida socialmente" (Teixeira, 2003, p. 73). Embora Telles (2003, p. 132) considere que a classificação racial brasileira é em grande parte ambígua, na Pesquisa Datafolha de 1995, em que seu trabalho é baseado, $88 \%$ das pessoas foram consistentemente classificadas como brancas ou negras (pardos e pretos) tanto pelo entrevistador como pelo entrevistado (Telles, 2003, p. 115).

Todos os brancos são formados em sociedades onde o exercício cotidiano de seu poder se traduz em imagens negativas e preconceituosas em relação ao negro. Mesmo os negros não estão imunes ao preconceito contra o negro, ou seja, o preconceito pode ser interiorizado por pessoas do próprio grupo discriminado, com fortes impactos sobre sua auto-estima (Fausto, 1984, p. 55). 
Objetivamente, no Brasil, a população é dividida em duas categorias, uma branca e outra não branca, formada por pretos e descendentes (pelo menos aqueles que trazem na pele e/ou no corpo as marcas da origem) mesmo que esses descendentes sejam também descendentes de brancos. A análise conjunta de pretos e pardos justifica-se porque o padrão de rendimento médio por escolaridade, experiência e outras variáveis socioeconômicas é extraordinariamente semelhante entre pretos e pardos e substancialmente diferente entre estes e as demais categorias de raça/cor (Silva, 1980).

A identidade de pretos e pardos começou a ser reconstruída por parte dos afro-descendentes brasileiros na década de 1980 do século passado sob a denominação de negra, termo que no período escravocrata estava associado ao escravo rebelde, em contraposição ao cativo fiel, denominado preto (Schwarcz, 1998, p. 225-226).

A partir destas considerações, no decorrer deste trabalho utilizam-se duas categorias agregadas: uma negra, composta por pretos e pardos (46\% da população em 2001); e outra não negra, composta em sua grande maioria por brancos (além de amarelos e indígenas). A participação da população negra no total da população brasileira, que é hoje a mesma que por ocasião da abolição, não permite a utilização do conceito de minoria para a população afro-descendente no país. O conceito de minoria, que muitas vezes é empregado para a população negra, reflete na verdade a participação minoritária de negros entre as elites econômicas, políticas e intelectuais do Brasil. Neste trabalho não se fará referência a minorias, como as populações indígenas, física e culturalmente dizimadas, porque se acredita que elas carecem de políticas de ação afirmativa muito mais particularizadas (Heringer, 1999, p. 5).

\section{CONCENTRAÇÃO RACIAL DO RENDIMENTO}

De acordo com os dados da PNAD (IBGE, 2002), embora representassem $46 \%$ da população, os negros eram responsáveis por apenas $27 \%$ do rendimento domiciliar per capita total do país; os não-negros, que representavam $54 \%$ da população, somavam $73 \%$ do rendimento, o que fornece um quadro do nível de concentração racial do rendimento no Brasil em 2001. 
Em relação à injustiça racial, a questão negra é muitas vezes intencionalmente subordinada à questão da injustiça social. Para o marxismo ortodoxo, a situação dos negros é explicada quase que exclusivamente pela sua posição econômica como classe trabalhadora. O racismo seria utilizado pela classe dominante para dividir os trabalhadores, como esclarece Hasenbalg (1979, p. 109). Guimarães (1995, p. 42) considera que, deste ponto de vista, a democracia racial seria um ideal a ser conquistado pelas lutas de classes. A situação dos negros seria a mesma dos trabalhadores pobres e, portanto, resolvido o problema da pobreza no Brasil (de negros e brancos), estar-se-ia resolvendo o problema da injustiça racial. Levantar a questão da raça, além de fomentar o racismo, teria o ônus de dividir e enfraquecer a luta das camadas progressistas pela justiça social no país.

Esta simplificação tem como origem a sobreposição parcial (interseção) da questão negra e da pobreza no país ("a maioria dos negros é pobre e a maioria dos pobres é negra”). De acordo com a figura 1, 52,6 milhões de brasileiros, doravante denominados pobres, auferiram rendimento domiciliar per capita de até 0,5 salário mínimo por mês em 2001 (soma das primeiras duas colunas da figura 1). No mesmo ano, 76 milhões de brasileiros com rendimento domiciliar declarado se autoclassificaram como pretos ou pardos (soma das colunas de negros), dos quais 34,1 milhões eram pobres (primeira coluna). Os negros pobres somavam $44,8 \%$ do total da população negra enquanto que os não-negros pobres somavam apenas $20,9 \%$ do total da população não negra.

À medida que aumenta o rendimento domiciliar per capita, cai a participação dos negros na população. O contingente não negro equivalia, aproximadamente, à metade da população negra na classe com rendimento até 0,5 salário mínimo; na classe com rendimento acima de 9 salários mínimos, o contingente não negro atingia nove vezes a população negra (ver figura 1).

Se, de acordo com a figura 1, os negros se concentravam nas camadas pobres da população, essa concentração se agrava quando se passa do número de pessoas para o total do rendimento domiciliar per capita por classe de rendimento (ver figura 2). A distância entre negros e não-negros aumenta em todas as classes de rendimento quando se passa do número de pessoas para o total do rendimento. No Brasil, em 2001, em termos agregados, os não-negros (88,8 milhões) eram $17 \%$ mais numerosos que os negros 
Figura 1: População por rendimento domiciliar per capita - Brasil, 2001

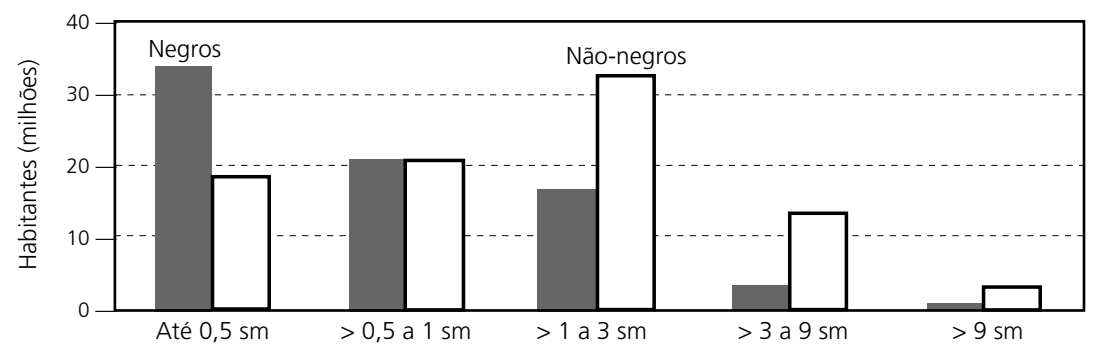

Classe de rendimento

Fonte: Elaborado a partir de IBGE (2002).

Figura 2: Total do rendimento domiciliar per capita - Brasil, 2001

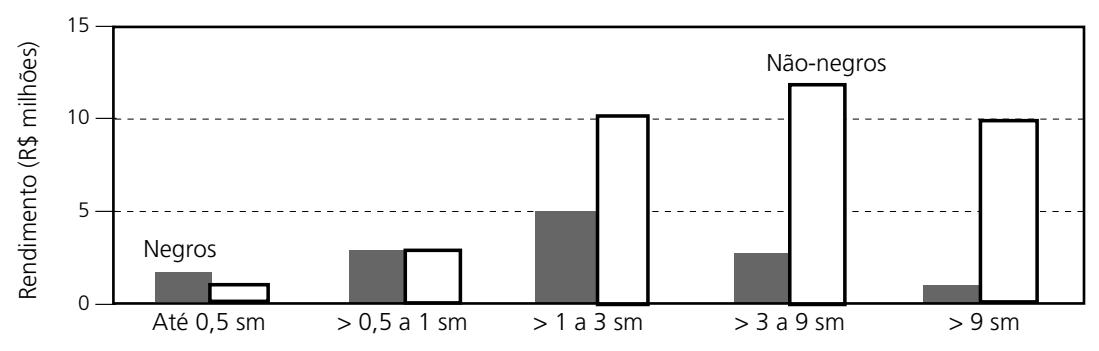

Classe de rendimento

Fonte: Elaborado a partir de IBGE (2002).

(76 milhões), mas seu rendimento domiciliar per capita ( $\mathrm{R} \$ 36$ bilhões) era $175 \%$ superior ao rendimento dos negros ( $\mathrm{R} \$ 13,1$ bilhões).

A questão negra, desta forma, não se resume à questão social. Embora não se devam medir esforços para a erradicação da injustiça social no país, a questão racial constitui um capítulo à parte. Os negros estão sim sobre-representados nas camadas pobres, de baixa escolaridade, no trabalho infantil, no trabalho informal, nos empregos domésticos, de lavadeira/passador, lixeiro, varredor etc.; por outro lado, estão excluídos ou sub-representados entre advogados, juízes, médicos, dentistas, engenheiros, professores universitários etc. (Henriques, 2001). Em 2002, dos 1.057 diplomatas em atividade, somente oito eram negros, $0,8 \%$ do total (Studart, 2002). Políticas universalistas, portanto, não são suficientes para enfrentar a desigualdade e a discriminação racial no país (Jaccoud e Beghin, 2002, p. 43). 
O valor do rendimento pessoal do trabalho de negros é sempre inferior ao das demais categorias de raça/cor, mesmo quando se controla o nível de escolaridade (Hasenbalg, 1979; Silva, 1980). A participação média de negros na população com 19 e mais anos de idade, ocupada e com rendimento positivo, era de $43 \%$. Por anos de estudo, essa participação variava de $68 \%$ no estrato com menos de um ano de estudo a $18 \%$ no estrato com 12 e mais anos de estudo; por décimos de rendimento, variava de $67 \%$ no décimo mais pobre a $18 \%$ no décimo mais rico. Contudo, a questão da injustiça racial fica ainda mais evidente quando se considera que, para um mesmo nível de escolaridade, o rendimento dos negros também era sempre inferior ao rendimento dos não-negros. A tabela 1 apresenta a participação percentual de negros no total da população por anos de estudo e décimos de rendimento pessoal de todos os trabalhos em 2001. A participação de negros, para cada um dos níveis de escolaridade, cai à medida que sobe o nível de rendimento das pessoas ocupadas.

As taxas de desemprego também são sempre maiores para o segmento negro da população. Entre janeiro e junho de 2001, a taxa de desemprego de negros em relação a não-negros nas regiões metropolitanas de São Paulo, Salvador e Porto Alegre registraram um diferencial de respectivamente

Tabela 1: Participação percentual de negros por escolaridade e rendimento* - Brasil, 2001

\begin{tabular}{|c|c|c|c|c|c|c|c|c|c|c|c|}
\hline \multirow{2}{*}{$\begin{array}{l}\text { Anos de } \\
\text { estudo }\end{array}$} & \multicolumn{10}{|c|}{ Décimos de rendimento pessoal de todos os trabalhos } & \multirow[b]{2}{*}{ Total } \\
\hline & 1 & 2 & 3 & 4 & 5 & 6 & 7 & 8 & 9 & 10 & \\
\hline 0 & 75 & 73 & 70 & 65 & 62 & 60 & 61 & 55 & 51 & 41 & 68 \\
\hline 1 & 68 & 67 & 68 & 59 & 58 & 55 & 55 & 55 & 48 & 25 & 62 \\
\hline 2 & 67 & 66 & 63 & 62 & 55 & 55 & 50 & 49 & 37 & 30 & 59 \\
\hline 3 & 69 & 60 & 58 & 53 & 47 & 49 & 45 & 39 & 38 & 24 & 53 \\
\hline 4 & 59 & 55 & 55 & 47 & 45 & 44 & 37 & 36 & 26 & 22 & 45 \\
\hline 5 & 62 & 59 & 57 & 51 & 46 & 41 & 39 & 39 & 30 & 29 & 47 \\
\hline 6 & 61 & 60 & 61 & 56 & 47 & 43 & 45 & 40 & 35 & 32 & 50 \\
\hline 7 & 65 & 62 & 59 & 52 & 43 & 45 & 38 & 39 & 30 & 38 & 47 \\
\hline 8 & 58 & 53 & 58 & 49 & 41 & 43 & 37 & 36 & 28 & 22 & 41 \\
\hline 9 & 54 & 56 & 61 & 54 & 41 & 44 & 34 & 32 & 34 & 26 & 44 \\
\hline 10 & 59 & 55 & 55 & 48 & 42 & 40 & 38 & 40 & 31 & 24 & 42 \\
\hline 11 & 57 & 52 & 54 & 46 & 40 & 39 & 32 & 32 & 28 & 22 & 36 \\
\hline $12+$ & 25 & 25 & 37 & 23 & 27 & 26 & 22 & 23 & 19 & 13 & 18 \\
\hline Total & 67 & 62 & 59 & 51 & 45 & 43 & 37 & 35 & 27 & 18 & 43 \\
\hline
\end{tabular}

Fonte: Elaborado a partir de IBGE (2002).

* Pessoas com 19 e mais anos de idade, ocupadas com renda positiva. 
Tabela 2: Participação de negros e pobres na população das grandes regiões - Brasil, 2001* (\%)

\begin{tabular}{lccc}
\hline & Negros & Até $0,5 \mathrm{sm}^{* *}$ & 0 a 3 anos de estudo*** \\
\hline Nordeste & 70,2 & 55,3 & 43,6 \\
\hline Centro-Oeste & 55,3 & 26,9 & 25,8 \\
\hline Sudeste & 35,7 & 20,3 & 20,2 \\
\hline Sul & 15,5 & 20,4 & 20,8 \\
\hline
\end{tabular}

Fonte: Elaborado a partir de IBGE (2002).

* O Norte foi excluído porque a PNAD não inclui a maior parte da zona rural da região.

** Rendimento domiciliar per capita.

*** População maior de 10 anos.

$41 \%, 50 \%$ e $66 \%$. E as taxas de desemprego de negros eram também maiores para todos os graus de escolaridade (Dieese, 2001, p. 6).

Quanto mais longe se está do fim do sistema escravista, menor o poder explicativo da escravidão e da origem social dos negros como causa de sua subordinação social corrente; e maior o poder explicativo do racismo e da discriminação contemporâneos. As oportunidades dos filhos negros são menores que as dos não-negros mesmo quando se controla a posição social das famílias de origem (Hasenbalg, 1979, p. 198-199); e o negro tem também maior propensão a perder posições sociais conquistadas por seus pais (Hasenbalg e Silva, 1999).

A questão da justiça racial, poder-se-ia acrescentar, além de se sobrepor parcialmente à questão da justiça social, também se sobrepõe parcialmente à questão da justiça regional (que, por sua vez, estão sobrepostas parcialmente entre si). A tabela 2 apresenta a participação percentual de negros e pessoas com rendimento domiciliar per capita até 0,5 salário mínimo na população das grandes regiões do país em 2001 (o Norte foi excluído desta análise porque a PNAD não inclui a maior parte da zona rural da região). Como o poder de compra do real difere por região (e não existe medida atual para sua mensuração), agregou-se à tabela 2 a participação de pessoas com 0 a 3 anos de estudo na população maior de 10 anos de idade. Os dados da tabela 2 indicam que as regiões mais pobres do país também apresentavam maior participação de negros em sua população. Embora as questões social, regional e racial se sobreponham, elas devem ser tratadas de forma singular. No processo de efetiva democratização do país, avanços em cada uma dessas instâncias terão reflexos favoráveis na promoção da eqüidade em todos os diferentes recortes da sociedade brasileira. 


\section{DISTRIBUIÇÃO DO RENDIMENTO POR RAÇA}

O fato de o rendimento estar concentrado entre não-negros (e de os negros estarem concentrados nas camadas pobres da população) pode levar à equivocada dedução de que o rendimento no Brasil, por categoria de raça/cor, é significativamente mais bem distribuído que o rendimento da população total do país. Mas a má distribuição do rendimento no Brasil extrapola a questão racial e se reproduz entre negros e entre não-negros (da mesma forma que extrapola a questão regional e se reproduz nas várias regiões pobres e ricas do país).

A figura 3 apresenta a curva de Lorenz do rendimento domiciliar per capita em 2001 para a população total, para a população negra e para a população não negra do país (a distribuição do rendimento por raça foi também construída para níveis menores de agregação, por unidades da federação, com resultados semelhantes aos apurados para o Brasil). O rendimento domiciliar per capita dos negros era relativamente mais bem distribuído que o rendimento dos não-negros que, por sua vez, apresentava distribuição semelhante ao rendimento da população total. Os negros, que apresentavam menores níveis de rendimento que os não-negros, também apresentavam

Figura 3: Rendimento domiciliar per capita - Brasil, 2001 (curva de Lorenz)

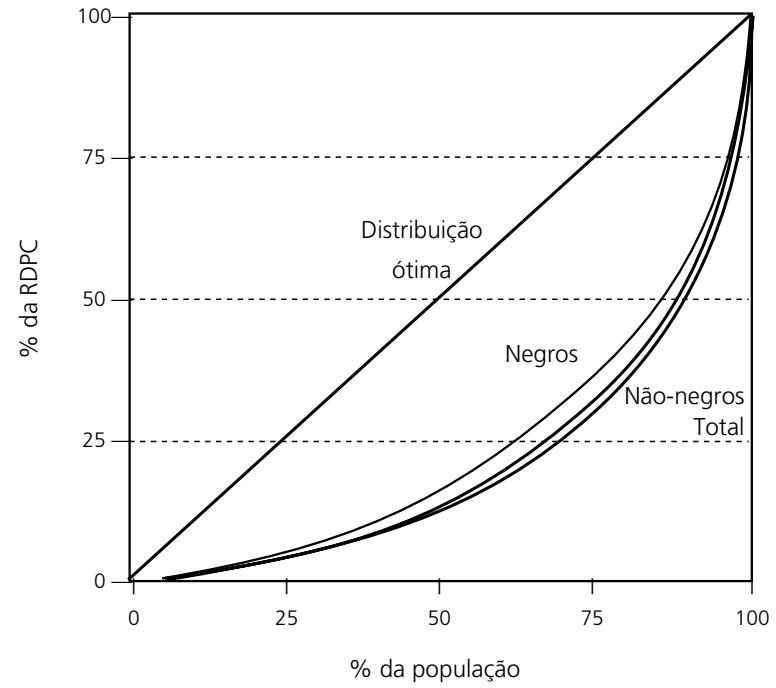

Fonte: Elaborado a partir de IBGE (2002). 
menor dispersão do rendimento. Mas, quando comparada a indicadores internacionais, a melhor distribuição do rendimento entre negros é pouco significativa.

A tabela 3 compara os coeficientes de Gini do Brasil $(59,4)$, do Brasil não negro $(57,8)$ e do Brasil negro $(53,4)$ aos coeficientes dos grandes países da América Latina e desenvolvidos. Entre os 116 países com estimativas aceitáveis pelo Banco Mundial (a Argentina não figura entre eles), os coeficientes de Gini variavam de 21,5 a 63,2 (BM, 2002). Os coeficientes de Gini nos países da América Latina relacionados na tabela 3 variavam de 44,9 a 59,4 e nos países desenvolvidos, de 25,9 a 37,9. Em relação aos indicadores internacionais, o nível de concentração do Brasil negro atingia, portanto, um patamar semelhante ao do país como um todo.

A má distribuição do rendimento no Brasil pode ser melhor apreendida quando se explicitam os percentis dos rendimentos (ver tabela 4). O rendimento domiciliar per capita mensal dos 50\% mais pobres do país (excluídos os habitantes da zona rural da antiga região Norte) era igual ou menor que R\$ 150 em 2001. Mas, também, não era preciso ser milionário para fazer parte do clube dos $5 \%$ mais ricos do país. Um brasileiro com rendimento domiciliar per capita mensal de R \$ 1.005,50 em 2001 fazia parte dos 5\% mais ricos do país, que reuniam 8,2 milhões de habitantes. Como bem lembrado por Hoffmann (2001), pessoas relativamente ricas para a distribuição de renda no Brasil costumam se considerar "pobres" ou, quando muito, "classe média".

Por raça, o rendimento domiciliar per capita mensal dos 50\% não negros mais pobres do país era igual ou inferior a $\mathrm{R} \$ 210$ e o dos $50 \%$ negros mais

Tabela 3: Coeficientes de Gini

\begin{tabular}{llllll}
\hline País & Ano & Gini & País & Ano & Gini \\
\hline Brasil* & 2001 & 59,4 & EUA & 1991 & 37,9 \\
\hline Brasil não negro* & 2001 & 57,8 & Japão & 1990 & 35,0 \\
\hline Chile & 1994 & 56,5 & França & 1984 & 34,9 \\
\hline Venezuela & 1990 & 53,8 & Inglaterra & 1991 & 32,4 \\
\hline Brasil negro* & 2001 & 53,4 & Alemanha & 1984 & 32,2 \\
\hline Colômbia & 1991 & 51,3 & Itália & 1991 & 32,2 \\
\hline México & 1992 & 50,3 & Canadá & 1991 & 27,7 \\
\hline Peru & 1994 & 44,9 & Espanha & 1989 & 25,9 \\
\hline
\end{tabular}

Fonte: Elaborado a partir de IBGE (2002), BM (2002).

* Rendimento domiciliar per capita. 
Tabela 4: Percentis do rendimento domiciliar per capita mensal por raça/cor - Brasil, 2001

\begin{tabular}{|c|c|c|c|c|c|c|}
\hline & \multicolumn{2}{|c|}{ Brasil } & \multicolumn{2}{|c|}{ Brasil negro } & \multicolumn{2}{|c|}{ Brasil não-negro } \\
\hline & Valor $(R \$)$ & Pessoas (mil) & Valor $(R \$)$ & Pessoas (mil) & Valor $(R \$)$ & Pessoas (mil) \\
\hline \multicolumn{7}{|c|}{$\begin{array}{l}\text { Pessoas com rendimento } \\
\text { abaixo do percentil }\end{array}$} \\
\hline 10 & 37.50 & 16469.2 & 28.75 & 7573.6 & 54.00 & 8817.8 \\
\hline 20 & 60.00 & 30771.5 & 45.00 & 14401.1 & 90.00 & 17264.8 \\
\hline 30 & 88.33 & 49396.3 & 61.25 & 22783.6 & 125.00 & 26184.8 \\
\hline 40 & 116.67 & 65728.9 & 82.22 & 30410.2 & 166.67 & 35155.1 \\
\hline 50 & 150.00 & 80790.6 & 102.50 & 37953.2 & 210.00 & 44369.6 \\
\hline 60 & 196.00 & 98893.5 & 132.20 & 45617.7 & 273.33 & 53267.3 \\
\hline 70 & 260.00 & 115110.6 & 171.67 & 53222.8 & 366.67 & 62047.2 \\
\hline 80 & 375.00 & 131717.7 & 225.00 & 60683.1 & 522.50 & 71036.0 \\
\hline $90(a)$ & 640.00 & 148302.6 & 351.67 & 68431.7 & 890.00 & 79922.6 \\
\hline \multicolumn{7}{|c|}{$\begin{array}{l}\text { Pessoas com rendimento } \\
\text { igual ou maior que o percentil }\end{array}$} \\
\hline $90(b)$ & 640.00 & 16544.9 & 351.67 & 7606.5 & 890.00 & 8886.7 \\
\hline 95 & 1005.50 & 8243.6 & 522.00 & 3804.8 & 1375.00 & 4441.0 \\
\hline 99 & 2500.00 & 1687.5 & 1200.00 & 746.6 & 3125.00 & 894.7 \\
\hline Total $(a+b)$ & - & 164847.5 & - & 76038.2 & - & 88809.3 \\
\hline$(\%)$ & - & 100.0 & - & 46.1 & - & 53.9 \\
\hline
\end{tabular}

Fonte: Elaborado a partir de Ibge (2002).

pobres do país era igual ou inferior a $\mathrm{R} \$ 102$. Por outro lado, um não-negro com rendimento domiciliar per capita mensal de $\mathrm{R} \$ 1.375$ fazia parte dos $5 \%$ não-negros mais ricos do país; e um negro com rendimento domiciliar per capita mensal de $\mathrm{R} \$ 522$ fazia parte dos 5\% negros mais ricos do país. Ou seja, a má distribuição do rendimento entre negros independe da existência de negros milionários. Dada a extrema pobreza da maior parte dos negros no país, um negro com renda domiciliar per capita mensal de R \$ 522 fazia parte da elite dos 5\% de negros mais ricos do Brasil e um negro com renda domiciliar per capita mensal de $\mathrm{R} \$ 1.200$ fazia parte do $1 \%$ ou 746,6 mil negros mais ricos do país.

\section{CONSIDERAÇÕES FINAIS}

Apesar do mito da democracia racial, o rendimento no Brasil está concentrado na categoria não negra da população, que aufere rendimento maior que os negros, mesmo quando controlado o nível de escolaridade dos trabalhadores. 
A má distribuição do rendimento no Brasil se reproduz na má distribuição do rendimento entre negros e não-negros, o que significa que a injustiça social no Brasil extrapola a questão racial e se manifesta também entre as categorias de raça/cor. O fato de os negros apresentarem má distribuição do rendimento reforça as considerações de que a questão racial no Brasil deve ser tratada independentemente da questão social. A má distribuição do rendimento se reproduz entre negros, apesar de os negros estarem concentrados nas camadas mais pobres da população, isto é, apesar da concentração racial do rendimento.

O preconceito e a discriminação racial sem tensões e inquietação social restringem as oportunidades econômicas, educacionais, sociais e políticas dos negros, o que contribui para perpetuar o passado no presente e impede a existência e o surgimento de uma verdadeira democracia racial no Brasil (Fernandes, 1972, p. 73). O mito da democracia racial brasileira legitima as desigualdades raciais e impede que a situação real se transforme numa questão pública. A harmonia racial tem sido utilizada pela elite do país para enaltecer a sociedade multirracial brasileira. Nos anos 60 e 70 do século passado, durante o regime militar, a discussão sobre as desigualdades raciais foi desencorajada no Brasil (o quesito raça/cor foi excluído do Censo de 1970). A inclusão do quesito raça/cor em questionários e documentos oficiais ainda hoje é muitas vezes identificada como racista. Apesar da excelente qualidade de informação das estatísticas vitais em São Paulo, 25,4\% das declarações de nascimento no estado e $45,5 \%$ na capital não traziam o campo raça/ cor preenchido em 2000 (Fseade, 2001).

Nos Estados Unidos, os resultados e a eficácia das políticas oficiais de ação afirmativa, em vigor desde os anos 60 do século passado, continuam sendo debatidos em tom eminentemente ideológico (Heringer, 1999). Em documento recente, o Massachusetts Institute of Technology (MIT, 2002), centro de excelência acadêmica internacionalmente reconhecido, reafirma seu compromisso com políticas de ação afirmativa que garantam a todos os segmentos da sociedade igualdade de oportunidades de acesso à educação e ao emprego no instituto. De acordo com o MIT, as políticas de ação afirmativa, além de contribuírem para a igualdade de oportunidades, contribuem também para a formação de profissionais qualificados para atuar em sociedades que apresentam diversidade étnica. 
O MIT considera que as políticas de ação afirmativa trouxeram resultados significativos nas últimas décadas, mas considera também que elas continuam sendo necessárias porque uma real igualdade de oportunidades ainda está longe de ter sido atingida. O Plano de Ação Afirmativa do instituto apresenta as iniciativas de suas várias unidades em relação ao emprego de funcionários e professores, além de acesso e assistência financeira a alunos dos cursos de graduação e pós-graduação (MIT, 2002).

A Terceira Conferência Mundial contra o Racismo, realizada em Durban, na África do Sul, em setembro de 2001, estimulou a apresentação de diversas propostas e medidas de ação afirmativa no Brasil, de bolsas de estudo para cursos preparatórios e para universidades a cotas para universidades públicas, empregos públicos e empresas prestadoras de serviços ao setor público. A identificação étnica, para efeito das políticas de ação afirmativa, segue o critério de autodenominação entre as cinco categorias do IBGE (branca, preta, amarela, parda, indígena) que, embora limitado, é o critério oficial, tradicional e compatível com as pesquisas de corte nacional (Heringer, 2002; Jaccoud e Beghin, 2002, p. 57-64).

Especificamente em relação à educação, é importante esclarecer que não basta garantir o acesso de negros à universidade. A grande parte do reduzido número de alunos negros que hoje ingressa na universidade não consegue concluir o curso. Neste sentido, as políticas de ação afirmativa devem, além de garantir o ingresso de negros na universidade, garantir também sua permanência indispensável para a titulação (Teixeira et al., 2002, p. 3).

Em relação ao acesso à educação, pode-se utilizar o sistema de cotas ou metas. No sistema de metas, todos os candidatos devem ser inicialmente aprovados por mérito, isto é, atingir a nota mínima de aproveitamento exigida para acompanhar o curso em questão. Os candidatos aprovados por mérito devem ser então divididos em categorias de raça/cor de modo a preencherem as vagas definidas pelo sistema de metas. Se as metas definidas pelos cursos não forem atingidas, pode-se pensar em organizar cursinhos de preparação para o exame de seleção (com bolsas de estudo, a exemplo do Itamaraty-CNPq, 2002), buscar aumentar as oportunidades da populaçãoalvo de ingressar, permanecer e se titular no curso imediatamente anterior ao curso em questão, e assim por diante. Entre várias iniciativas neste sentido, vale citar a experiência da Educafro em São Paulo e no Rio, entidade 
com núcleos pré-vestibulares e que potencializa a entrada e a permanência de negros pobres nas universidades (Educafro, 2003).

Pesquisas de opinião pública dão suporte à hipótese de que a oposição às políticas de ação afirmativa cresce com o nível de escolaridade e rendimento. Quem mais se opõe a essas políticas é a elite branca do país que, no sistema político brasileiro, é aquela que tem voz. Diante das políticas de ação afirmativa, as elites brasileiras tendem sempre a apoiar somente programas universalistas para a redução da pobreza ou para melhorar a distribuição de renda do país (Telles, 2003, p. 288). Andrews (1998, p. 287) considera que o movimento negro causa profunda inquietação aos brancos de classe média e alta do Brasil, que são muito conscientes de que estão sentados no topo de uma sociedade muito tensa, em que a maioria da população sofre as aflições diárias da pobreza e da raça.

O artigo veemente de Roberto Mangabeira Unger (2004), publicado na imprensa paulista, serve para ilustrar essa tendência. Embora considere que a injustiça racial seja um mal arraigado em nossa sociedade e em nossos corações, Unger acredita que o resultado de "reservas raciais" será a simples promoção de uma "elite afro-brasileira" que não afetará a miséria da "massa negra”. Mas, como afirma Telles (2003, p. 216), é exatamente no topo da estrutura social brasileira que residem as maiores disparidades raciais. Os cidadãos brancos compõem a vasta maioria das classes médias e alta, deixando aos negros a condição de serem pobres e o estigma de serem marginais.

No lugar das políticas de ação afirmativa, Unger (2004) sugere que seja dada preferência não para negros, mas sim para pobres estudantes talentosos (a maioria dos beneficiados seria automaticamente "de cor"), que seriam preparados para formar uma contra-elite morena, negra e pobre, capaz de disputar os lugares de nossa elite branca de herdeiros, com impacto transformador "imediato" sobre a sociedade brasileira. No lugar de uma elite negra, o poético fim "imediato" de toda e qualquer elite.

\section{REFERÊNCIAS BIBLIOGRÁFICAS}

ANDREWS, G. R. (1998) Negros e brancos em São Paulo (1888-1988). Bauru: Edusc.

BM (Banco Mundial) (2002) Gini Index. Washington: WB. Disponível em http://www. worldbank.org/research/growth/dddeisqu.htm (1/12/2002). 
CNPq (Conselho Nacional de Desenvolvimento Científico e Tecnológico) (2002) Bolsas para afro-descendentes (Chamada no 01/2002). Brasília: CNPq. Disponível em www.cnpq. br/noticias/informes/inform_160502.htm (10/6/2002).

DIEESE (2001) Boletim Dieese (edição especial, novembro). São Paulo: Dieese.

EDUCAFRO (2003) Entrevista com Frei David. Disponível em www.opasquim21.com.br/ edicoes/055 (12/8/2003).

FAUSTO, B. (1984) Crime e cotidiano: a criminalidade em São Paulo (1880-1924). São Paulo: Brasiliense.

FERNANDES, F. (1972) O negro no mundo dos brancos. São Paulo: Difusão Européia do Livro.

FSEADE (Fundação Seade) (2001) Sistema de estatísticas vitais (microdados). São Paulo: Fseade (CD-ROM).

FURTADO, C. (2000) Formação econômica do Brasil. São Paulo: Publifolha.

GUIMARÃES, A. S. A. (1995) “Racismo e anti-racismo no Brasil”. Novos Estudos CEBRAP n. 43, p. 26-44.

HASENBALG, C. A. (1979) Discriminação e desigualdades raciais no Brasil. Rio de Janeiro: Graal.

— Brasil”. In: C. A. Hasenbalg, N. V. Silva e M. Lima (orgs.), Cor e estratificação social. Rio de Janeiro: Contracapa.

HENRIQUES, R. (2001) Desigualdade racial no Brasil: evolução das condições de vida na década de 90. Rio de Janeiro: IPEA. Texto para Discussão n. 807. Disponível em www.ipea.gov.br

HERINGER, R. (1999) Desigualdades raciais e ação afirmativa no Brasil: reflexões a partir da experiência dos EUA. Rio de Janeiro: Universidade Candido Mendes (mimeo).

(2002) "Ação afirmativa e combate às desigualdades raciais no Brasil: o desafio da prática”. Encontro Nacional de Estudos Populacionais, 13, 2002, Ouro Preto. Anais... Recife: ABEP. CD-ROM, 16 p. Disponível em www.abep.org.br

HOFFMANN R. (2001) "Distribuição da renda no Brasil: poucos com muito e muitos com muito pouco”. In: L. Dowbor e S. Kilsztajn (orgs.), Economia social no Brasil. São Paulo: Senac.

IBGE (1986) Estatísticas históricas do Brasil. Rio de Janeiro: IBGE.

(2002) Pesquisa nacional por amostra de domicílios - 2001 (microdados). Rio de Janeiro: Ibge (CD-ROM).

JACCOUD, L., BEGHIN, N. (2002) Desigualdades raciais no Brasil: um balanço da intervenção governamental. Brasília: IPEA. Disponível em http://www.ipea.gov.br/TemasEspeciais/ desigualdades/Parte1.pdf; Parte2.pdf (8/11/2003).

MIT (Massachusetts Institute of Technology) (2002) Affirmative Action Plan Summary. Massachusetts: MIT. Disponível em web.mit.edu/hr/aa/plan/aap.html (3/4/2003).

PETRUCCELLI, J. L. (2000) A cor denominada - estudo das informações do suplemento da PME, julho/98. Rio de Janeiro: Ibge/Dpis. 
SCHWARCZ, L. M. (1998) "Nem preto nem branco, muito pelo contrário, cor e raça na intimidade”. In: L. M. Schwarcz (org.), História da vida privada no Brasil (4): contrastes da intimidade contemporânea. São Paulo: Companhia das Letras, p. 175-243.

SILVA, N. V. (1980) "O preço da cor: diferenciais raciais na distribuição da renda no Brasil”. Pesquisa e Planejamento Econômico, v. 10, n. 1, p. 21-41.

SKIDMORE, T. E. (1976) Preto no branco: raça e nacionalidade no pensamento brasileiro. Rio de Janeiro: Paz e Terra.

SEGATO, R. L. (1995) Santos e daimones: o politeísmo afro-brasileiro e a tradição arquetipal. Brasília, Editora Universidade de Brasília.

STUDART, H. (2002) A nova face da diplomacia. São Paulo: Isto é, 4/12/202. Disponível em http://www.terra.com.br/istoedinheiro/275/economia 275_face_diplomacia. htm\#

TEIXEIRA, M. P. et al. (2002) "Projeto Políticas de ação afirmativa nas universidades Federal Fluminense e Federal do Mato Grosso". Encontro Nacional de Estudos Populacionais, 13, 2002, Ouro Preto. Anais... Recife: ABEP. CD-ROM, 41 p. Disponível em www. abep. org.br

(2003) Negros na universidade: identidade e trajetórias de ascensão social no Rio de Janeiro. Rio de Janeiro: Pallas.

TELLES, E. (2003) Racismo à brasileira. Rio de Janeiro: Relume Dumará, 347 p.

UNGER, R. M. (2004) “Justiça racial já”. São Paulo: Folha de S. Paulo (13/1/2005). 